\title{
COMPARISON OF PROGRESSION OF SPONTANEOUS VERSUS INDUCED LABOR IN PRIMI AND MULTIPAROUS WOMEN
}

\author{
ANITA MADAN, SUJATA SHARMA, YASHASVINI YEDLA*, JAGDEEP KAUR
}

Department of Obstetrics and Gynecology, Government Medical College, Amritsar, Punjab, India. Email: yash.yadukula@gmail.com Received: 10 March 2021, Revised and Accepted: 10 May 2021

\section{ABSTRACT}

Objectives: The objectives of the study were to compare progression of spontaneous versus induced labor in primigravida and multigravida women.

Methods: Pregnant women admitted in Labor room of Bebe Nanaki mother and Child Care Centre, Amritsar during April 2019-March 2020 were selected for this study. A total of 200 pregnant women were selected and divided into two groups. Women in group A were induced while in group B were women with spontaneous onset of labor. Labor progression in both was compared.

Results: In group A, the mean duration of the active phase in primigravida was $4.08 \pm 2.30 \mathrm{~h}$ and in multigravida was $4.02 \pm 2.20 \mathrm{~h}$. In group $\mathrm{B}$, the mean duration of active phase in primigravidas was $7.24 \pm 1.39 \mathrm{~h}$ and in multigravidas was $6.48 \pm 1.40 \mathrm{~h}$. In group A, the mean duration of the second stage in a primigravida was $25.5 \pm 8.15 \mathrm{~min}$ and in a multigravida was $17.38 \pm 9.95 \mathrm{~min}$. In group $\mathrm{B}$, the mean duration of the second stage in a primigravida was $41.3 \pm 9.6 \mathrm{~min}$, while in a multigravida was $22.72 \pm 6.2 \mathrm{~h}$.

Discussion: The mean duration of active phase in group A in the primigravida and multigravida was almost similar, showing that induction does not have any effect on the duration of active phase. The mean duration of the second stage of group A in primigravida was 25 min and multipara was 17 min showing that induction reduces the duration of the second stage.

Conclusion: Induction of labor when done at the right gestational age for correct indication is beneficial to women as it reduces the complications caused due to the continuation of high-risk pregnancies.

Keywords: Induction of labor, Multigravida, Primigravida, Spontaneous labor.

(C) 2021 The Authors. Published by Innovare Academic Sciences Pvt Ltd. This is an open access article under the CC BY license (http://creativecommons.org/ licenses/by/4.0/) DOI: http://dx.doi.org/10.22159/ajpcr.2021v14i6.41439. Journal homepage: https://innovareacademics.in/journals/index.php/ajpcr

\section{INTRODUCTION}

"Induction of labor" is defined as the initiation of uterine contractions before the onset of labor for the purpose of vaginal delivery, while augmentation of labor refers to the stimulation of spontaneous contractions that are considered inadequate because of failed cervical dilatation and fetal descent [1]. Induction of labor is one of the most important tools in the obstetrician's armamentarium with the aim of achieving a successful vaginal delivery when the continuation of pregnancy is a potential threat to the life of the mother and the unborn baby.

Induction is done after assessing the BISHOPS SCORE. In this study, Modified Bishops score was used.

This study was done to determine how the progression of labor in primigravida and multiparous women who presented with spontaneous labor differed from those who are electively induced, using a World Health Organization (WHO) modified partograph. The objective of this study was to

1. To compare progression of spontaneous versus induced labor in primi and multigravida women using WHO partograph

2. To study the advantages and disadvantages of induction of labor

\section{METHODS}

Pregnant women admitted in Labor room of Bebe Nanaki mother and Child Care Centre, Amritsar during April 2019-March 2020 were selected for this study. A total of 200 pregnant women were selected and divided into two groups. In one group, labor was induced by any method (either medical or surgical), while in the other group were women with spontaneous labor and progression of labor in both was noted on modified WHO partograph. The fetal outcome was noted. The study was conducted after approval from Institutional Ethics Committee, Government Medical College, Amritsar and informed consent from patients was enrolled in the study.

The two groups were managed as follows:

\section{Group A}

In women whose bishops score was $<6$, induction of labor was done using one of the methods (Prostaglandins E2 (PGE2), PGE1 (Misoprostol), (Balloon Devices: Foley Catheter, Membranes Sweeping).

\section{Group B}

Primi and multiparous women who presented with spontaneous onset of labor with a favourable cervix (bishop score $>6$ ).

Induction was preferably started early in the morning of the patients who fulfilled the inclusion criteria and had a Bishop score of $<6$.

\section{Management of labor}

- Labor was monitored using partograph

- Augmentation with oxytocin was done if cervical dilatation was $<1 \mathrm{~cm} / \mathrm{h}$. Fetal monitoring was done by auscultation

- Facilities for immediate cesarean delivery were kept readily available in case of failed induction or fetal distress.

On admission, initial PV was done and Bishop Score assessed. The patient was allowed to progress on her own. PV was repeated after $4 \mathrm{~h}$ or on the rupture of membranes. Partograph was plotted in active phase of labor. In case of PV findings crossing the alert line, labor was augmented with oxytocin. 
If the Bishops score was $<5$, induction of labor was done using one of the methods (Prostaglandins-PGE2 gel, PGE1, Foley's catheter, Amniotomy, Membrane stripping). The patient was reassessed if there was draining PV or after $6 \mathrm{~h}$ when an intracervical gel was used or after $4 \mathrm{~h}$ when PGE1 misoprostol was used.

\section{RESULTS}

Out of 100 cases of group A, 78 (78\%) cases had delivered vaginally, while $22(22 \%)$ cases had a cesarean delivery. Out of 100 cases of group B, 97 (97\%) cases had a normal vaginal delivery (NVD) whereas, $3(3 \%)$ cases had a cesarean delivery Table 1.

Out of 100 cases of group A, 2 (2\%) patients had cephalopelvic disproportion (CPD), 4 (4\%) patients had failure of progression of labor, fetal distress was seen in $12(12 \%)$ cases and $4(4 \%)$ cases had meconium-stained liquor (MSL) while 78 (78\%) patients had NVD Table 2.

Out of 100 cases of group B, 1 (1\%) case had CPD, 1 (1\%) case had fetal distress and MSL was seen in $1(1 \%)$ case and 97 (97\%) patients had a successful vaginal delivery.

Out of 100 cases of group A, the mean duration of active phase of labor was $4.07 \pm 2.27 \mathrm{~h}$, out of 100 cases of group $B$, the mean duration of active phase of labor was $6.9 \pm 1.44 \mathrm{~h}$ Table 3 .

Out of the 100 cases of group A, the mean duration of the second stage of labor was found to be $25.5 \pm 18.86 \mathrm{~min}$, while out of the 100 cases of group B, the mean duration of the second stage of labor was $38.15 \pm 12.47$ min Table 4 .

In group $\mathrm{A}$, the mean duration of active phase of labor in a primigravida was $4.08 \pm 2.30 \mathrm{~h}$ and in multigravidas, it was found to be $4.02 \pm 2.20 \mathrm{~h}$ Graph 1.

In group $\mathrm{B}$, the mean duration of active phase of labor in a primigravida was $7.24 \pm 1.39 \mathrm{~h}$ and in multigravidas was $6.48 \pm 1.40 \mathrm{~h}$ Table 5 .

Table 1: Mode of delivery

\begin{tabular}{llll}
\hline Mode of delivery & Group A & Group B & Total \\
\hline NVD & 78 & 97 & 175 \\
LSCS & 22 & 3 & 25 \\
Total & 100 & 100 & 200 \\
\hline
\end{tabular}

$\mathrm{p}=0.001$, LSCS: Lower segment caesarean section, NVD: Normal vaginal delivery

Table 2: Reason for failure of induction

\begin{tabular}{llll}
\hline Reason for failure of induction & Group A & Group B & Total \\
\hline CPD & 2 & 1 & 3 \\
Failure of progress of labor & 4 & 0 & 4 \\
Fetal distress & 12 & 1 & 13 \\
MSL & 4 & 1 & 5 \\
\hline
\end{tabular}

$\mathrm{p}=0.003$, CPD: Cephalopelvic disproportion, MSL: Meconium stained liquor

Table 3: Mean duration of active phase

\begin{tabular}{llll}
\hline Active phase & $\mathbf{n}$ & Mean \pm SD & Std. error mean \\
\hline Group A & 100 & $4.07 \pm 2.27 \mathrm{~h}$ & 0.227 \\
Group B & 100 & $6.90 \pm 1.44 \mathrm{~h}$ & 0.144 \\
\hline
\end{tabular}

Table 4: Mean duration of second stage of labor

\begin{tabular}{llll}
\hline Second stage & $\mathbf{n}$ & Mean \pm SD & Std. error mean \\
\hline Group A & 100 & $25.25 \pm 18.86 \mathrm{~min}$ & 1.885 \\
Group B & 100 & $38.15 \pm 12.47 \mathrm{~min}$ & 1.247 \\
\hline
\end{tabular}

Out of group A, the mean duration of the second stage of labor in a primigravida was $25.5 \pm 8.15 \mathrm{~min}$ and in a multigravida, it was 17.38 \pm 9.95 min (Graph 2 and Table 6).

Out of group B, the mean duration of the second stage of labor in a primigravida was $41.3 \pm 9.6 \mathrm{~min}$, while in a multigravida, it was $22.72 \pm 6.2 \mathrm{~h}$ (Graph 2 and Table 6).

Out of 100 cases in group A, the mean appearance, pulse, grimace, activity, and respiration (APGAR) score was $7.42 \pm 1.8$, while in 100 cases of group B, the mean APGAR score of the newborn was $8.16 \pm 0.6$ Table 7

\section{DISCUSSION}

The maternal characteristics differed significantly among the groups with respect to the presence of antenatal complications such as pregnancy-induced hypertension, gestational diabetes mellitus, prelabor rupture of membranes, and intrauterine growth retardation. They were present significantly higher percentage in the induced group, that is, $63 \%$, whereas it was only $31 \%$ in induced group.

Our study concluded that women with spontaneous onset of labor had high chances of vaginal delivery than those of induced groups. In our study, out of 100 cases of the spontaneous group, 3\% had cesarean delivery while $22 \%$ had cesarean section among the induced group. This was in favor of a previous study conducted by Sagarika and Lakshmi, where the rate of cesarean section was about $31 \%$ among the patients with induced labor [2]. In a study conducted by Grivell et al., it was concluded that the rate of cesarean section is increased when induction is done for non-recognized indications [3]. A study by Roos et al. also observed that there is a fivefold increased risk of cesarean delivery among nulliparous women [4]. Jonsson et $a l$. inferred that electively induced labor doubled the risk of cesarean section compared with spontaneous labor onset and the risk was more than tripled when cervical ripening was used [5]. In our study, there was almost seven-fold risk of cesarean section among patients who had induced labor than patients who went into spontaneous labor as there was an increased risk of fetal distress, MSL, and failure of induction.

Table 5: Mean duration of active phase in primigravida and multigravida

\begin{tabular}{llll}
\hline Gravida & n & Mean \pm SD & Std. error mean \\
\hline Group A & & & \\
Primi & 78 & $4.08 \pm 2.30 \mathrm{~h}$ & 0.260 \\
Multi & 22 & $4.02 \pm 2.20 \mathrm{~h}$ & 0.469 \\
Group B & & & \\
Primi & 55 & $7.24 \pm 1.39 \mathrm{~h}$ & 0.188 \\
Multi & 45 & $6.48 \pm 1.40 \mathrm{~h}$ & 0.208 \\
\hline
\end{tabular}

Table 6: Showing mean duration of second stage of labor in primigravida and multigravida

\begin{tabular}{llll}
\hline & Gravida & N & Mean \pm SD \\
\hline Group A & Primi & 71 & $25.51 \pm 8.15 \mathrm{~min}$ \\
& Multi & 29 & $17.38 \pm 9.95 \mathrm{~min}$ \\
Group B & Primi & 54 & $41.30 \pm 9.60 \mathrm{~min}$ \\
& Multi & 46 & $22.72 \pm 6.20 \mathrm{~min}$ \\
\hline
\end{tabular}

Table 7: The mean APGAR scores of the newborn

\begin{tabular}{lll}
\hline APGAR & $\mathbf{n}$ & Mean \pm SD \\
\hline Group A & 100 & $7.42 \pm 1.80$ \\
Group B & 100 & $8.16 \pm 0.60$ \\
\hline APGAR: Appearance, pulse, grimace, activity, and respiration &
\end{tabular}




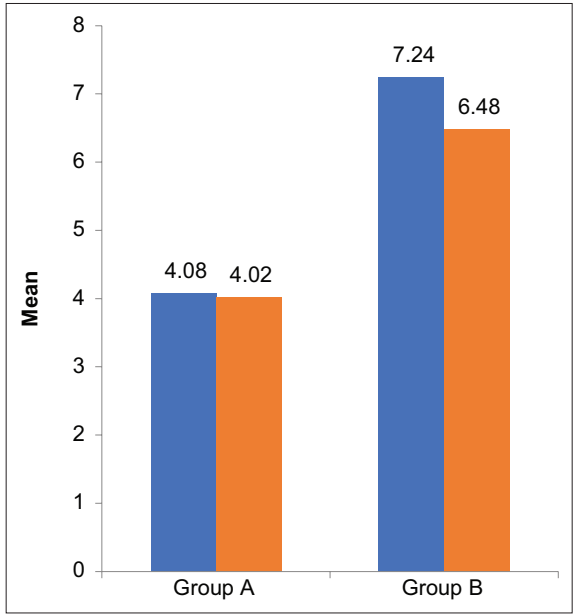

Graph 1: Mean duration of active phase in primigravida and multigravida

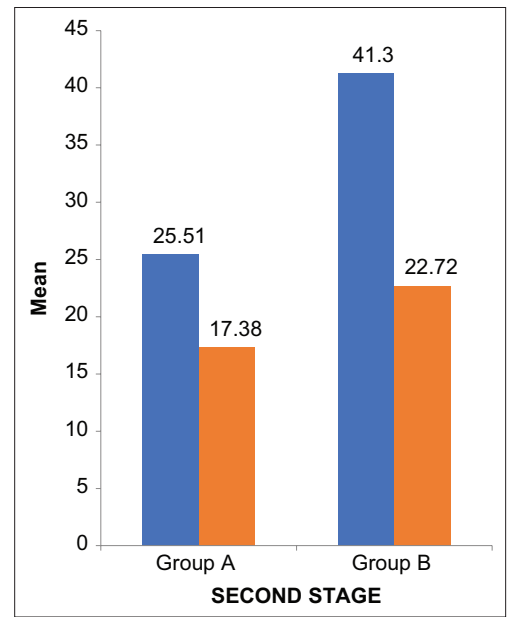

Graph 2: Mean duration of the second stage of labor in primigravida and multigravida

The indication for cesarean section was different among the 2 groups. The most common indication for cesarean section among the induced group was fetal distress comprising of $54 \%$ among the induced group. This is in contrast to the study conducted by Abisowo et al., where CPD was the most common indication [6].

The mean duration of active phase of labor of the induced group in the primigravida was $4.08 \mathrm{~h}$ and multigravida was $4.02 \mathrm{~h}$ showing that induction does not have any effect on the duration of active phase of labor. The mean duration of the second stage of labor of the spontaneous group in primigravidas was $41 \mathrm{~min}$ and in multipara was $22 \mathrm{~min}$. This was in contrast to findings of the study conducted by Østborg et al., who concluded that active phase of labor was longer in induced than in spontaneous labors in nulliparous women [7].

The mean duration of the second stage of labor of the induced group in primigravida was 25 min and multipara was 17 min showing that induction reduces the duration of the second stage of labor.

APGAR score of the newborn was assessed which determines the success of a delivery. The mean APGAR score of the newborn in the spontaneous group was about 8.1, whereas the mean APGAR score in the induced group was 7 , which shows that the newborn of the spontaneous group has a better score than the newborn of the induced group. This was in contrast to the findings of the study conducted by Singh et al. [8]. The studies conducted by Patel et al. [9] and Yadav et al. [10] who showed that there was no significant difference in the APGAR scores of the two groups.

So taking into account of both maternal and fetal outcomes, there is a strong association between cesarean delivery rate and induction of labor, compared to spontaneous labor. Induction did not increase perinatal morbidity and mortality. Correct choice of mode of induction, monitoring the fetus and mother during intrapartum period vigilantly plays a crucial role in the outcome.

\section{CONCLUSION}

Induction of labor, when done at the right gestational age, for a correct indication, is beneficial to the women as it not only reduced the anxiety among the women and her relatives but also reduces the complications caused due to the continuation of high-risk pregnancies.

To conclude, induction of labor is associated with a shorter active and second stage of labor in primigravidas, but this difference was not significantly seen in multiparous women. Induction of labor is also associated with an increased risk of cesarean section, the most common indication for cesarean being fetal distress. Increased rate of cesarean deliveries in the induced group may also be due to the fact that this group included the patients who were high risk and had comorbidities such as hypertension, preeclampsia, postdated, and $\mathrm{Rh}$-ve pregnancy.

APGAR scores of the newborn of the spontaneous group were better in comparison to the induced group.

\section{AUTHORS' CONTRIBUTIONS}

Dr. Anita Madan and Dr. Sujata Sharma conceived the idea of this study "COMPARISON OF PROGRESSION OF SPONTANEOUS VERSUS INDUCED LABOR IN PRIMI AND MULTIPAROUS WOMEN.” Dr. Yashasvini developed the theory and performed the computations. Dr. Anita Madan and Dr. Sujata Sharma verified the analytical methods. Dr. Jagdeep Kaur encouraged Dr. Yashasvini to investigate and supervised the findings of the work. All authors discussed the results and contributed to the final manuscript.

\section{CONFLICTS OF INTEREST}

The authors declare that there are no conflicts of interest.

\section{AUTHORS' FUNDING}

The authors received no financial support for the research and/or publication of this article.

\section{REFERENCES}

1. Konar H. Induction of labor in textbook of obstetrics. In: Dutta's DC, editor. Textbook of Obstetrics. 8th ed. New Delhi: Jaypee Brothers Medical Publishers Pvt. Ltd.; 2015. p. 598.

2. Sagarika B, Lakshmi MM. Elective induction versus spontaneous labor at term: Prospective study of outcome and complications. Int J Reprod Contracept Obstet Gynecol 2017;6:4899-907.

3. Grivell RM, Reilly AJ, Oakey H, Chan A, Dodd JM. Maternal and neonatal outcomes following induction of labor: A cohort study. Acta Obstet Gynecol Scand 2012;91:198-203.

4. Roos N, Sahlin L, Ekman-Ordeberg G, Kieler H, Stephansson O. Maternal risk factors for postterm pregnancy and cesarean delivery following labor induction. Acta Obstet Gynecol Scand 2010;89:1003-10.

5. Jonsson M, Cnattingius S, Wikstrom AK. Elective induction of labor and the risk of cesarean section in low-risk parous women: A cohort study. Acta Obstet Gynecol Scand 2013;92:198-203.

6. Abisowo OY, Oyinyechi AJ, Olusegun FA, Oyedokun OY, Motunrayo AF, Abimbola OT. Feto-maternal outcome of induced vs spontaneous labour in a Nigerian Tertiary Maternity Unit. Trop J Obstet Gynaecol 2017;34:21-7.

7. Østborg TB, Romundstad PR, Eggebø TM. Duration of the active phase 
of labor in spontaneous and induced labors. Acta Obstet Gynecol Scand 2017;96:120-7.

8. Singh A, Rao SB, Sherigar B, D'souza R, Soumya R, Kaveri V. Comparison of progress of labour and maternofetal outcome among induced versus spontaneous labour in nulliparous women using modified WHO partograph. Int J Reprod Contracept Obstet Gynecol 2018;7:415-8.
9. Patel O, Pradhan S, Naik B. Comparative study of labour progress and delivery outcome among induced versus spontaneous labour in nulliparous women using modified WHO partograph. J Evol Med Dent Sci 2017;6:1844-9.

10. Yadav K, Ranga M, Nama A. Comparative study of induced and spontaneous labour in nulliparous women using modified WHO partograph. Int J Reprod Contracept Obstet Gynecol 020;9:2014-9. 